\title{
Confronting Unique Problems With Twins
}

\author{
Nancy L. Segal \\ Department of Psychology, California State University, USA
}

\begin{abstract}
Eamilies with twins occasionally confront unique problems warranting considerable professional attention. The possibility that twins may be less likely to be admitted to private schools of their choice, due to reduced financial contributions from family members, was recently raised. Specifically, two twin children have two sets of grandparents, while two non-twin children have four sets of grandparents; thus, schools would profit more highly by admitting non-twins. This sets the stage for reviewing steps that some universities and businesses have taken to offset the financial burdens of rearing multiples. Next, a research review of four twin studies follows. Findings on gluten sensitivity, tremors, communicative adaptability and serological differences are summarized. A tour of a fascinating twin exhibit at the Teylers Museum, in the Netherlands, concludes this column.
\end{abstract}

\section{Twins: Not Just in Science, But in Society}

Twins' vast research potential makes it easy to forget that their lives (and those of their families) may take unusual twists and turns. Prudent scientists will, therefore, seek opportunities for interactions with twins beyond formal laboratory settings. Twins' special issues and circumstances may ultimately emerge as the focus of new or ongoing investigations. The story that follows is exemplary.

Two years ago, while waiting to be seated at a restaurant, a couple with young $\mathrm{MZ}$ twin girls joined the line. Always eager to identify interesting cases, I left my companions to chat briefly with the family. The mother was eager to talk at some length so we exchanged business cards. We spoke later that week, at which time I was introduced to a unique, school-related "twin problem" that left me perplexed and somewhat angry. Details of this story have been altered slightly in the interest of confidentiality.

It seemed that public schools in the couple's city were undergoing problematic change so, like other mothers and fathers, they sought enrollment of their twins in private school. Such decisions are never simple, demanding months of institutional research, family interviews and child assessments. Given the keen competition for space, only the best qualified students are admitted. It was at this juncture that the twins' mother defined the problem: Families with school-age twins (no matter how bright or talented) find themselves on a different playing field from families with singletons. Why? The reason is that private schools are eager to maximize future funding sources, so assess families (i.e., parents and grandparents) with some consideration of their potential as financial donors. Families with twins are disadvantaged because the numbers of different parent and grandparent sets are correspondingly reduced, relatives to families with singletons. In other words, contributions from a twin pair's grandparents would be comparable to those from a nontwin's grandparents, not twice as much. Schools would, thus, reap greater monetary gain by admitting two non-twin children from different families, rather than two twin children from the same family. Such interests clearly work to the detriment of multiple birth families, either by denying admission to two qualified students, or by admitting only one child. Either outcome could conflict with parents' carefully formulated plans for their twins' education. This problem is, no doubt, magnified for families with triplets, quadruplets and more.
School administrators can find many reasons for denying admission to students so it is difficult to determine the gravity or prevalence of this problem. (I have not surveyed private schools with this issue in mind. However, I view the family's concern seriously and believe it warrants closer attention from educational professionals.) Some parents of twins, seeking creative solutions to surprising problems, unwittingly establish what I think of as "underground networks" for information exchange and support. These hidden social links differ from (but may develop out of) those from more formal parenting clubs and organizations. At the core are the mothers and fathers whose special circumstances force them to find ways of confronting and coping with the unimagined challenges of rearing twins. The relatively small numbers of affected families, and their desire to confront unusual school problems cautiously so as not to jeopardize their children's situation, may explain why some school problems are not better known.

Address for correpsondence: Nancy Segal, Department of Psychology, California State University, Fullerton, CA 92834 USA. Email: nsegal@fullerton.edu 
Fortunately, the present story had a happy ending and the twin girls were jointly admitted to the school of their parents' choice. However, this singular situation forces administrators, practitioners and researchers to consider ways that both public and private secondary and higher educational institutions might be more sensitive to the circumstances of families with twins. Some other sectors of society, aware of the over $50 \%$ increase in multiple births since 1980 (Ventura, Martin, Curtin, Menacker, \& Hamilton, 2001), have found innovative antidotes to the financial strains of raising multiples. I will review some of these and suggest new ones in the hope that educators and others might follow suit.

- Higher Education. Lake Erie College, in Painesville, Ohio offers "two-for-one" scholarships to twins (New York Times, 1982; Lake Erie College Financial Aid Officer, personal communication, 1998). This practice was initiated in 1982 by an anonymous donor. One twin receives full funding, while the co-twin pays his or her own way, although these roles are reversed every year to ease financial burdens (www.TwinsFoundation.com/scholarships.htm, 2001). Three twin pairs, from Ohio, Wisconsin and New York, accepted this offer for the first Fall enrollment. Four scholarships are offered each year and are renewable for three-year periods.

- Sterling College, in Sterling, Kansas, offers a one-half tuition award to each member of qualified twin pairs. If additional assistance is needed, twins may apply for other sources of funding (www. TwinsFoundation. com/scholarships.htm, 2001).

- Northeastern Oklahoma A \& M College, in Miami, Oklahoma, offers free room scholarships for twins (www. TwinsFoundation. com/scholarships.htm, 2001).

- Clothing and More. In 1997, a Twins and Triplets Club was established by One Step Ahead, a company manufacturing clothes, toys and care products for families with young twins (One Step Ahead Catalogue, 1998). Duplicate items are discounted by $20 \%$, triplicate items are discounted by $30 \%$, and so on. A special product line, Tykes Alike, is also available for families with multiples.

- More Clothing Discounts. The Burlington Coat Factory offers 20\% discounts for twins if a second similar item is purchased (www. Twinsworld.com, 2001). A mother of twins offers discounted, coordinated outfits for multiples (twinoutfitters.com). Some corporations are waiting to hear from twins, parents of twins and others to assess specific needs before cutting costs. (Contact twinsworld-feedback215@lb.bcentral.com).

- Layettes. Several exclusive shops, such as the toy store, F.A.O. Schwarz, and clothing outfitter, Baby Gap, are offering products and shopping guidelines with multiples in mind (New York Times, 2001). The department store, Saks Fifth Avenue, has followed suit, but added a discount for twins: layettes priced at $\$ 350$ for singletons are $\$ 600$ for twins. (The $\$ 100$ discount is, of course, offset by the initially high price of the product from this exclusive store.) Interestingly, the writer of the article on these products concluded by stating, "If only Harvard would do the same." This casual comment hits at the heart of a problem which has so far been addressed by only the three small colleges named above, i.e. escalating college costs that are especially daunting for twins - yes, if only Harvard would do the same...

- Insurance. A twin' protection policy was developed in 1992 by the Polish insurer, Warta (Wall Street Journal, 1992). Families are paid the equivalent of $\$ 35.00$ for returns of $\$ 4,200.00$ if pregnancies result in twins.

- The British Insurance Company, Eagle Star, developed a plan in 1996 to provide financial benefits to parents expecting multiple birth children (Coppard, personal communication, 1996).

Note: The programs listed above are neither exhaustive, nor complete. They include only the twin-based discounts known to this author. News of other such opportunities for twins and families with twins would be welcome.

Programs like those listed above could be instituted by other universities, businesses and companies. For example, two-for-one services, such as sports club memberships and tax payments are discounted for couples, but such benefits have not been available for twins. Two-for-one toys, apparel, medical bills and amusement park passes would help defray costs for families needing assistance. The price of higher education is, of course, daunting for many families with twins who (unlike families with non-twin children) are responsible for two tuitions simultaneously. Lake Erie College's program was clearly ahead of its time yet, curiously, has not been adopted by other institutions. University faculty with twin investigators could also benefit by attracting twin research participants. As a runner and frequent participant in races and fun runs, I would urge organizers to consider twofor-one entry fees for twins. In fact, many events sponsored by road runners clubs benefit a charity or cause - a "run for twin research" would attract considerable interest from many segments of the population, as well as support a chosen twin project.

Society needs to look more carefully at health and other resources available to multiple birth children and families. Information and services are often provided only by local twins' organizations who operate with limited budgets. Increased attention and assistance to twins' well-being might be society's repayment for their generous use of twin images in the media, twin-like phrases in the news, twin metaphors in literary works and twins' growing popularity in research. If twins and other multiples are treated unfairly because of perceived strains on school funding sources or other inequities, it is time to address these concerns. 


\section{Research Reviews}

\section{Twin Study of Gluten Sensitivity}

Gluten sensitivity involves anomalous response to gluten, a component of wheat, barley and rye. The two major classes of reactions include celiac disease (a condition in which the small intestine fails to digest and absorb food; Bantam Medical Dictionary, 194) and dermatitis (inflammation of the skin; On-line Medical Dictionary, 1997). Some additional silent forms of the disorder are also considered to reflect sensitivity to gluten. Genetic and environmental effects on this condition were assessed via longitudinal study of five MZ female twin pairs, in Italy (Baerdella, Fredella, Prampolini, Marino, Conte \& Giunta, 2000). Twins were born between 1971 and 1987 and were followed on a regular basis. Three pairs showed concordance for celiac disease, although in one pair co-twins' symptoms appeared ten years apart. Two pairs showing discordance included co-twins diagnosed with celiac disease and dermatitis, respectively. The investigators cautioned, however, that later onset of the disorder may be possible in the case of these discordant sets.

Genetic influence on gluten sensitivity was supported by concordance in three pairs, as well as by positive family histories. The type and timing of the disorder can, however, vary even in $\mathrm{MZ}$ twins, suggesting environmental effects. The nature of these environmental influences, as well as those that may explain $\mathrm{MZ}$ twin discordance for gluten sensitivity, remain unknown. Larger samples of affected twins and adoptees (individuals who are genetically unrelated, but exposed to similar diets) would be informative.

\section{Twin Tremors}

Tremors are rhythmical, alternating movements that may affect any part of the body (Bantam Medical Dictionary, 1994). Essential tremors (ET), the most common variety, are associated with purposeful movements and motor activities (On-line Medical Dictionary, 1997). These symptoms have a suspected familial component. The first twin study of ET was recently published by Tanner, Goldman, Lyons, Aston, Tetrud, Welsh, Langston, \& Koller (2001). The sample included sixteen male twin pairs, identified through the National Academy of Sciences and National Research Council World War II Veterans Twin Registry. They were drawn from a group of 196 twins showing postural or kinetic tremor; however, 137 were excluded because the twin or his cotwin had Parkinson's Disease and 33 were excluded due to missing data. The remaining sixteen twins were members of $5 \mathrm{MZ}$ pairs and $11 \mathrm{DZ}$ pairs. Pairwise concordance rates were .60 and .27 for $\mathrm{MZ}$ and $\mathrm{DZ}$ twin pairs, respectively. These values suggest genetic influence, but as the authors rightly note, their findings must be viewed quite cautiously. The sample was extremely small and diagnosis of ET was based on a single examination. In addition, ET cases were identified in the course of screening for Parkinson's Disease patients, so it is likely that some relevant cases were overlooked. Finally, the sample included only males, precluding generalizability of the findings to females.

\section{Twins' Communicative Adaptability}

Twins' Communicative Adaptability. This interesting twin study originated from a theory of communicative adaptability, based on work by Beatty \& McCroskey (1997, 1998). These researchers proposed that stable individual differences in communication-related behavior reflect individual differences in the activation thresholds of neurobiological systems. These neurobiological systems are thought to be largely influenced by genetic effects. The investigators in the present study used a twin design to assess heritability of various dimensions of communicative adaptability. These dimensions, which represented five factors derived from factor analysis of the 30-item Communicative Adaptability Scale, included social composure, wit, articulation, social confirmation and appropriate disclosure. The 62 $\mathrm{MZ}$ and $43 \mathrm{DZ}$ twin pairs were identified at the annual Twinsburg, Ohio "Twins Days" Festival. Zygosity determinations were made by responses to questionnaire items concerning physical resemblance and confusion.

Heritabilities derived from Falconer's (1989) formula $\left(\mathrm{h}^{2}=2\left[\mathrm{MZ} \mathrm{r}_{\mathrm{i}}-\mathrm{DZ} \mathrm{r}_{\mathrm{i}}\right]\right)$ were high for Social Composure (.88) and Wit (.90), moderate for Social Confirmation (.36) and zero (.00) for both Articulation and Appropriate Disclosure. (It should be noted, however, that the authors substituted Pearson product-moment correlations for intraclass correlations, an incorrect procedure as stipulated by the above formula.) It was suggested that the difference in heritability between Social Composure and Wit, compared with the other three dimensions, may be associated with an "affect-performance distinction." That is to say, Social Composure and Wit concern subjects' feelings during social interaction and attempts at humor during uncomfortable encounters, respectively, reflecting genetically-based propensities for language engagement. In contrast, articulation and appropriate disclosure concern "effectiveness" or "correctness" of behavior, while social confirmation concerns elements of both affect and performance; these latter behaviors more be more reflective of social influence and experience. Various methodological features were also thought to explain the differential heritabilities. For example, answers to Social Composure and Wit items were based on self-knowledge, while answers to Articulation and Appropriate Disclosure items were affected by social feedback. To the extent that twins joined different social circles, subjective responses to their objectively similar behaviors may have differed somewhat.

It is gratifying that investigators from diverse disciplines are increasingly applying twin-based perspectives in their research programs. Continued efforts along these lines may disclose key information on the physiological mechanisms underlying individual differences in communicative processes. 


\section{Serological Differences in MZ Twins}

Finding meaningful physical differences between $\mathrm{MZ}$ co-twins can explain discordance in major medical conditions. In a search for significant disease-related factors, Swedish investigators focused on the serological profiles of three MZ twins pairs (two male and one female) discordant for multiple sclerosis (MS) (Bergkvist \&
Sandberg-Wollheim, 2001). The general finding that over $70 \%$ of $\mathrm{MZ}$ twins differ in this disorder implicates environmental effects, even though genetic factors have been detected.

Investigators gathered extensive medical and social life histories from each twin, including infectious diseases, allergies, vaccinations, animal exposures, occupational backgrounds and other factors. Some co-twin differences in serum titers (amount of antibody in serum; Bantam Medical
Dictionary, 1994) against some neurotropic microorganisms were found, but serum titers were generally quite similar within pairs. No clear pattern emerged with reference to the life experiences or physical differences of affected and unaffected co-twins. It was also noted that a similar study of eight Finnish twin pairs failed to draw meaningful associations between MS and exposure to various viruses. The roots of this debilitating disease remain a mystery.

\section{Artistic View from Abroad}

I am pleased to introduce Dr. Y. Michael Barilan, from Department of Internal Medicine B, Meir Hospital, Kfar Saba and Department of Behavioral Sciences, Sackler Faculty of Medicine, Tel Aviv University, Tel Aviv, Israel, who submitted his observations and insights on a twins exhibit held in the Netherlands.

\section{Twins in Art and Science: An Exhibition in the Teylers Museum, Haarlem.}

The Teylers Museum of Science in Haarlem, The Netherlands, is currently running a special exhibition entitled "Twins in Art and Science." The exhibition, although quite small, is an attempt to grapple with the metaphysical question of being a twin. The previous twin-related exhibition took place in the Mütter Museum of anatomy in Philadelphia, in 1995. It was dedicated to conjoined twins, and showed scientific and historical documents and images, not trying to recruit insight from the visual arts.

The Teylers exhibition is divided into four parts. The scientific section explains the process of twinning to the lay public. The research on the life and health of twins is represented only in the catalogue. There is also an extensive collection of photographs of twins, triplets and quadruplets. They mostly date back to the first half of this century, before reproductive technology was available, and when the mere survival of twins and triplets was still somewhat of an achievement to be proud of. About half the twins in a series of paintings from the $17 \mathrm{th}$ century are deceased. The Yoruba of Northern Nigeria, among whom a very high incidence of twin births occurs, create special figurines for their deceased twins. The small statuettes are placed in family celebrations.

Next, the visitor can look at documentary material about some conjoined twins with one staffed biheaded calf, one wax model of a man with a parasitic half-brother and some preserved conjoined fetuses. The last part of the exhibition is dedicated to artistic treatment of the subjects. Aside from a few archeological and ethnographic exhibits, the exhibition space is left to a series of pictures by the photographer Devid Teplica. He shows large black and white images of intertwined body parts of twins, such as an ear pressed closely and symmetrically to the ear of another. The artist plays on the ambiguity of twinning. All human bodies are in a way, identical to each other; the ears do not stand out as belonging to a set of twins because of visual proximity, but due to our knowledge of the subject matter. The arts teach us that seeing is much more than crisp observation, but what is the lesson regarding twins?
The notion of twins appeals to our visual cognition. Twins are not merely depicted as collaborating duos such as the "Mario Brothers" or other famous pairs from fiction and reality. The twins look alike and this is enhanced with identical clothes and gestures. The fantasy of doppelgänger foretells the search for human cloning. It is, on one hand, a wish for something stronger and more capable than the self, yet this wish expresses reconciliation and tenderness toward the fragile self by insisting on a copy, not a different and possibly better human body. The narcissism of the mirror image can be resolved by the acceptance of another human being as an Other.

The age of medical technology and public health has diminished the portentous image of twins in the common mind. We are now receptive to a different kind of imagery, that of fraternity, harmony and mutual respect.

\section{Address for Correspondence}

Y. Michael Barilan, M.D., 16 Mendele Street, Tel Aviv, Israel, Fax: 972-36200439, Phone: 972-5-2947753, bentovia@shani.net

\section{Acknowledgments}

I wish to thank Sister M. Kerckhof for translating from the Dutch and Ms. G. Worden, the curator of the Mütter Museum, for sharing the exhibition notes and other material. 


\section{References}

Baerdella, M. T., Fredella, C., Prampolini, L., Marino, R., Conte, D., \& Giunta, A.M. (2000). Gluten sensitivity in monozygous twins. A long-term follow-up of five pairs. American Journal of Gastroenterology, 95, 1503-1505.

Bantam Medical Dictionary.

Beatty, M. J., Marshall, L .A., \& Rudd, J. (200I). A twins study of communicative adaptability: Heritability of individual differences. Quarterly Journal of Speech, 87, 366-377.

Beatty, M. J., \& McCroskey, J. C. (1997). It's in our nature: Verbal aggressiveness as temperamental expression. Communication Quarterly, 45, 446-460.
Beatty, M. J., \& McCroskey, J. C. (1998). Interpersonal communication as temperamental expression: A communibiological paradigm. In J. C. McCroskey, \& M. J. Beatty (Eds.)., Communication and personality: Trait perspectives (pp. 4I-68). Cresskill, NJ: Hampton.

Bergkvist, M., \& Sandberg-Wollheim, M. (200I). Serological differences in monozygotic twin pairs discordant for multiple sclerosis. Acta Neurologica Scandinavica, 104, 262-265.

"College Bargain." New York Times. June 6, 1982; Lake Erie College Financial Aid Office (personal communication, February 6, 1998).

On-line Medical Dictionary.
One Step Ahead. (catalogue). Summer, 1998.

Segal, N. L. (2000). Entwined lives: Twins and what they tell us about human behavior. NY: Plume.

Tanner, C. M., Goldman, S. M., Lyons, K. E., Aston, D. A., Tetrud, J. W., Welsh, M. D., Langston, J. W., \& Koller, W.C. (200I). Essential tremor in twins: An assessment of genetic vs. environmental determinants of etiology. Neurology, 57, |389-139|.

Ventura, S. J., Martin, J. A., Curtin, S. C., Menacker, F., \& Hamilton, B. E. (200I). Births: Final data for 1999. National Vital Statistics Reports, 49, I-100.

"Very Expectantly Yours." New York Times. June 29, 2001 